\title{
A Selective Mutism Arising from First Language Attrition, Successfully Treated with Paroxetine-CBT Combination Treatment
}

\author{
Agostino Serra1, Paola Di Mauro', Claudio Andaloro', Luigi Maiolino', \\ Piero Pavone ${ }^{2}$, and Salvatore Cocuzza ${ }^{1 凶}$ \\ 1Department of Medical Surgical Specialties, ENT Clinic, University of Catania, Catania, Italy \\ ${ }^{2}$ Department of Pediatrics and Pediatric Emergency "Costanza Gravina”, University of Catania, Catania, Italy
}

After immersion in a foreign language, speakers often have difficulty retrieving native-language words and may experience a decrease in its proficiency, this phenomenon, in the non-pathological form, is known as first language attrition. Self-perception of this low nativelanguage proficiency and apprehension occurring when speaking is expected and, may sometimes lead these people to a state of social anxiety and, in extreme forms, can involve the withholding of speech as a primitive tool for self-protection, linking them to selective mutism. We report an unusual case of selective mutism arising from first language attrition in an Italian girl after attending a two-year "German language school", who successfully responded to a paroxetine-cognitive behavioral treatment (CBT) combination treatment.

Psychiatry Investig 2015;12(4):569-572

Key Words Selective mutism, Cognitive behavioral therapy, Paroxetine, Anxiety, Language attrition.

\section{INTRODUCTION}

Language loss covers a variety of linguistic phenomena: it can be the result of brain damage (aphasia) or senile dementia, or there can also be no pathology and it can develop as a result of an extensive and intensive period of second language (L2) contact. ${ }^{1}$

This last phenomenon is referred to as "first-language (L1) attrition". This term can be described as a process of dealing with "the non-pathological decrease of the mother tongue that had previously been acquired by an individual".'

In other words, attrition refers to the change in linguistic behavior due to a frequent use of the L2 language that becomes dominant making the L1 language subject to L2 influence or deterioration. L1 attrition is a process which is governed by two factors: the presence and development of the L2 system on the one hand, and the diminished exposure to and

Received: November 7, 2014 Revised: February 24, 2015

Accepted: March 17, 2015 Available online: September 30, 2015

$\triangle$ Correspondence: Salvatore Cocuzza, MD, PhD

Department of Medical Surgical Specialties, ENT Clinic, University of Catania, Via Santa Sofia, 78, Catania 95123, Italy

Tel: +39-347-5960303, Fax: +39-095-7335738, E-mail: s.cocuzza@unict.it

(a) This is an Open Access article distributed under the terms of the Creative Commons Attribution Non-Commercial License (http://creativecommons.org/licenses/by$\mathrm{nc} / 3.0$ ) which permits unrestricted non-commercial use, distribution, and reproduction in any medium, provided the original work is properly cited. use of L1 on the other. ${ }^{3}$ After immersion in a foreign language, speakers often have difficulty retrieving native-language words and may experience decreasing L1 proficiency. ${ }^{4}$

Self-perceived lower language proficiency and speaking pronunciation have been shown to be correlated with high levels of anxiety; furthermore, individual speaker's anxiety is higher as he or she perceives his or her ability as lower than other peoples. ${ }^{5,6}$ All of this can lead to a particular state of anxiety, social anxiety, or even social phobia, characterized by a fear of negative evaluation and concern about doing or saying something that will result in embarrassment or humiliation. ${ }^{7}$ This social fear in extreme form can involve the withholding of speech as a primitive tool for self-protection. ${ }^{8}$ Selective mutism (SM) is described as "persistent failure to speak in specific social situations where speaking is expected, despite speaking in other situations". Associations between selective mutism and social anxiety have been reported by several authors. ${ }^{10,11}$ In this work we report an unusual case of selective mutism arising from first language attrition in an Italian girl after attending a two-year "German language school", who successfully responded to a paroxetine-CBT combination treatment. 


\section{CASE}

A 171/2-year-old Italian girl was referred to our universitybased clinic for her persistent failure to speak for several months that occurred after an "unusual use" of her primary language upon returning from a two-year German language school. A speech and language pathologist (SLP), consulted for this unusual use of language, reported a partial replacement of her L1 (Italian) language system by L2 (German) with, both transfer of verb-second (V2) word order particular to L2 in place of SVO (subject-verb-object) L1 word-order and L1 lexical retrieval difficulties, which impeded the normal use of Italian, therefore a diagnosis of first language attrition was taken into account by the SLP. Although, over time, the girl showed a moderate improvement of her L1, her mistakes in Italian drew great attention to her, making her anxious and afraid to be with other people. Her anxiety about the possibil- ity of speaking incorrectly became so severe that mutism developed as a means of avoiding the feelings of anxiety and fear. The girl underwent a physical examination with evaluation of oral and sensory motor abilities with particular note to any orofacial abnormalities that might interfere with articulation revealing the absence of dysmorphic facial features, cleft palate or neck mass. Oropharynx, epiglottis, and uvula were easily visualized and found to be normal. Neurological difficulties, as evidenced by drooling, grimacing, muscular asymmetry, tongue and lip weakness, impaired sucking or swallowing that may impede the movements necessary for normal speech were absent. A hearing screening, performed to ensure that hearing difficulties were not contributing to the mutism, revealed a normal audiogram (15-20 dB in all frequencies) and normal peaks on tympanometry. The results of the clinical investigation, including an EEG with normal brain wave activity and a high-resolution $3 \mathrm{~T}$ magnetic resonance imag-
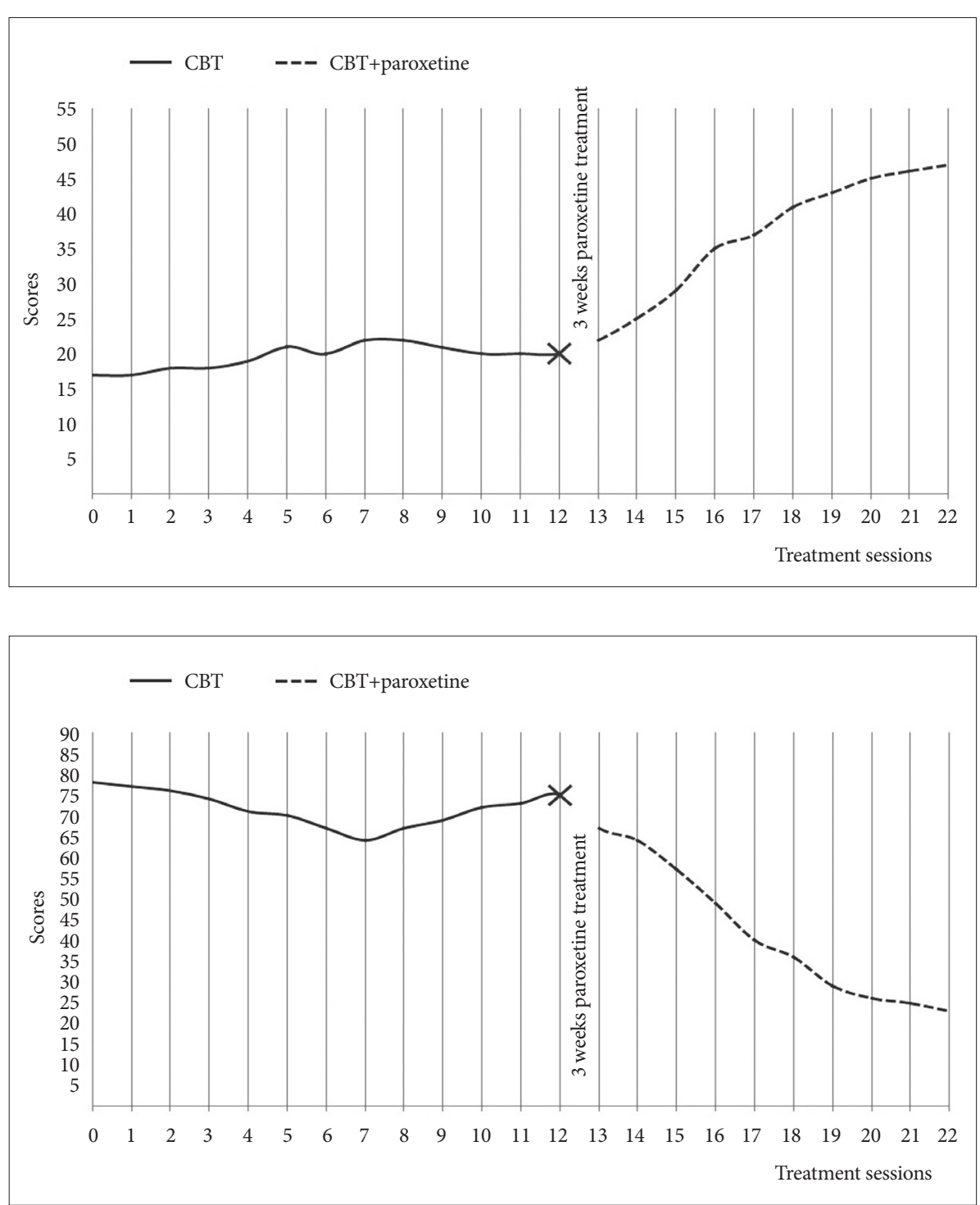

Figure 1. Graphic display of Selective Mutism Questionnaire scores during cognitive behavioral treatment (CBT) and CBT-paroxetine combo treatment.
Figure 2. Graphic display of Social Anxiety Scale for adolescents scores during cognitive behavioral treatment (CBT) and CBT-paroxetine combo treatment. 
ing (MRI) were within normal limits. At admission, the pediatrician was unable to engage the girl in spoken speech because she was mostly silent, for this reason a semi-structured parent clinical interview was conducted adopting the Anxiety Disorders Interview Schedule for DSM-IV-Parent Report (ADIS-IV-P), ${ }^{12}$ to gather precise information about symptom history including onset and conditions under which mutism occurs. According to the ADIS-IV-P, our girl met the criteria for SM with a clinical severity rating (CSR) of 6 and social phobia with a CSR of 5 on an eight-point scale.

Her mother also completed the Selective Mutism Questionnaire (SMQ), ${ }^{13}$ but as there are no known standardized SM measures for adolescents the SMQ was used as a proxy for measuring our girl's SM-related behaviors. On the SMQ our girl yielded a score of 13 , which was consistent with the mean for children with SM according to the Bergman report. During evaluation through direct observation, the girl appeared embarrassed, blushing and avoiding eye contact most of the time, except when she was alone with her parents in a room with the door closed, where she was able to speak without embarrassment with a clear speech pattern. The interview, questionnaire and observational data supported a diagnosis of $\mathrm{SM}$ as well as social phobia.

Given the frequent link between selective mutism and social anxiety disorder, it was decided to try a psychological intervention (CBT) followed by the addition, if necessary, of a selective serotonin reuptake inhibitor (SSRI) in order to form a combined approach CBT- SSRI. An evidence-based CBT modular approach, Modular Approach to Therapy for Children With Anxiety, Depression, Trauma, or Conduct Problems (MATCH),${ }^{14}$ was selected and adapted for the subject' age. An initial goal of treatment, before beginning the modular approach, was to increase the girl's verbal behavior with the therapist therefore, behavioral techniques of cognitive restructuring and reinforcement were used. After three of these sessions, the girl was able to make eye contact and interact with the therapist, increasing slightly her SMQ score to 17.

Considering the conceptualization of this case, MATCH modules that we proposed to use in our girl's treatment included: self-monitoring ("Fear Ladder"), education about anxiety ("Learning About Anxiety"), practice of feared situations ("Exposure"), and education about maintaining new skills ("Maintenance and Relapse Prevention").

At the end of each treatment session a rating of anxiety/ mutism severity was included to track her response to treatment over time, using: SMQ performed by her mother and Social Anxiety Scale for adolescents (SAS-A) ${ }^{15}$ performed by the girl herself (Figures 1 and 2).

Modular treatment started with the Learning About Anxiety module, continuing with the Exposure module in Sessions
3, however, she stopped without completing it after 10 unresponsive sessions, due to increasing anxiety when she was required to perform exercises. It was therefore decided to associate CBT with a paroxetine medication regimen $(20 \mathrm{mg} /$ daily) once daily at bedtime, with no adverse effects. After three weeks she appeared more relaxed with a lowered level of anxiety on CBT exposures, therefore she was able to finish all the MATCH modules that were proposed. The improvement was evident over the course of the second CBT module "Exposure", focused on the girl getting used to speaking in public places, at the beginning with her parents, then with her friends; with increased SMQ scores indicating more speech and diminished SAS-A scores that reflect reduced social anxiety (Figures 1 and 2). The Exposure module culminated in some participations in social situations (i.e., participating in birthday parties, ordering at a restaurant and meeting new peers). At the end of this module, the girl was able to engage in L1 speaking with unfamiliar people, asking questions, giving compliments, maintaining eye contact and speaking in a clear tone of voice. The last two treatment sessions involved the Maintenance and Relapse Prevention module to allow for a review of skills learned and to foster the girl's attribution of gains to the behaviors learned and performed in treatment. She received 10 sessions of active CBT-paroxetine combination treatment over the course of 10 weeks. The patient's dosage was reduced, performing a taper phase, after a three-month consultation when the girl, in agreement with her parents, appeared relaxed with a return to normal SAS-A values and was comfortable speaking with a return to normal SMQ values. On a one-year follow-up examination after the end of treatment, she confirmed no symptoms and full functioning.

\section{DISCUSSION}

Many theories attempt to explain the etiology of selective mutism such as: psychodynamic factors, family dysfunction, oppositional behavior, neurodevelopmental problems, social phobia and social anxiety. ${ }^{16}$ The last one, regarding our case, not only may have played a key role in linking the first language attrition to Selective mutism but may have also contributed to reinforcement of the inhibition of native language words and development of cognitive schemas that the world, and speaking in it, was unsafe. Upon her return from the German language school, the girl experienced both poor Italian proficiency and increased difficulties in returning to her native language. Fear of negative evaluation, self-perception of low language performance compared with her peers and apprehension occurring when she had to speak in Italian, led the girl to avoid situations where speaking is expected and she entered a social phobic state. The latter, in its extreme form, 
involved the withholding of her speech as a primitive tool for self-protection linking her to selective mutism.

Different strategies and interventions are needed for older children or teenagers, moreover, individual profiles tend to show more variation than with younger children because they are influenced by their great range of experiences, thus treatment needs to be tailored to their heterogeneous profile. This is why we chose a modular CBT approach, rather than a single approach, because it helped adapt treatment to the subject's age and gave the flexibility to address our girl's specific needs in order to personalize her treatment.

Current reports advocate the adjunct to behavioral therapy of SSRIs such as fluoxetine, sertraline and paroxetine to help patients with selective mutism and anxiety disorders who do not respond to psychotherapeutic interventions or with a poor outcome as shown by our subject during the first weeks of CBT alone treatment. ${ }^{17-19}$

Our girl showed a marked improvement within a few weeks from the introduction of paroxetine into the CBT intervention with lower anxiety associated to speech production and increased speaking behavior frequency in public settings, confirming that, in agreement with several literature reports, ${ }^{20,21}$ combined treatment CBT-SSRI is both an effective and welltolerated treatment and provides the best chance for a positive outcome in these disorders, asserting that the superiority of combination therapy might be due to the additive or synergistic effects of the two therapies.

Despite this, little is known about the synergistic effect mechanism and there are few data on optimal dosage and duration of treatment, because randomized studies or controlled trials comparing CBT, the use of a SSRI, or the combination of both therapies with a control are lacking.

For these reasons it is clear that treatment approaches to selective mutism merit further evaluation.

Future randomized controlled studies with larger sample sizes are necessary to evaluate the effectiveness of combined CBT-SSRI interventions for similar cases.

\section{REFERENCES}

1. Montrul S. Second language acquisition and first language loss in adult early bilinguals: exploring some differences and similarities. Second Lang Res 2005;21:199-249.
2. Köpke B, Schmid MS. Language Attrition: The Next Phase. In: Schmid MS, Köpke B, Keijzer M, Weilemar L, Editors. First Language Attrition: Interdisciplinary Perspectives on Methodological Issues. Amsterdam: John Benjamins, 2004, p.1-47.

3. Köpke B, Schmid MS, Keijzer M, Dostert S. Language Attrition: Theoretical Perspectives. Amsterdam: John Benjamins; 2007.

4. Levy BJ, McVeigh ND, Marful A, Anderson M. Inhibiting your native language: the role of retrieval-induced forgetting during second-language acquisition. Psychol Sci 2007;18:29-34.

5. Montgomery C, Spalding T. Anxiety and perceived English and French language competence of education students. Can J High Educ 2005;35: 1-26.

6. Szyszka M. Foreign language anxiety and self-perceived English pronounciation competence. Stud Second Lang Learn Teach 2011;1:283-300.

7. Turner SM, Beidel DC, Borden JW, Stanley MA, Jacob RG. Social phobia: Axis I and II correlates. J Abnorm Psychol 1991;100:102-106.

8. Anstendig KD. Is selective mutism an anxiety disorder? Rethinking its DSM-IV classification. J Anxiety Disord 1999;13:417-434.

9. American Psychiatric Association. Diagnostic and Statistical Manual of Mental Disorders, Fourth Edition, Text Revision (DSM-IV-TR). Washington DC: American Psychiatric Association; 2000.

10. Black B, Uhde TW. Psychiatric characteristics of children with selective mutism: a pilot study. J Am Acad Child Adolesc Psychiatry 1995; 34:847-856.

11. Black B, Uhde TW. Elective mutism is a variant of social phobia. J Am Acad Child Adolesc Psychiatry 1992;31:1090-1094.

12. Silverman W, Albano A. The Anxiety Disorders Interview Schedule for Children-IV (Child and parent versions). San Antonio: Psychological Corporation; 1996.

13. Bergman RL, Keller ML, Piacentini J, Bergman AJ. The development and psychometric properties of the selective mutism questionnaire. J Clin Child Adolesc Psychol 2008;37:456-464.

14. Chorpita BF, Weisz JR. Modular Approach to Therapy for Children with Anxiety, Depression, Trauma, or Conduct Problems [MATCH-ADTC]. Satellite Beach: PracticeWise; 2008.

15. La Greca AM. Social Anxiety Scales for Children and Adolescents: Manual and Instructions for the SASC, SASC-R, SAS-A (Adolescents) and Parent Versions of the Scales. Miami: University of Miami; 1998.

16. Viana AG, Beidel DC, Rabian B. Selective mutism: a review and integration of the last 15 years. Clin Psychol Rev 2009;29:57-67.

17. Turkiewicz G, Castro LL, Morikawa M, Costa CZ, Asbahr FR. Selective mutism and the anxiety spectrum--a long-term case report. Rev Bras Psiquiatr 2008;30:172-173.

18. Jainer AK, Quasim M, Davis M. Elective mutism: a case study. Int J Psychiat Clin Pract 2002;6:49-51.

19. Kaakeh Y, Stumpf JL. Treatment of selective mutism: focus on selective serotonin reuptake inhibitors. Pharmacotherapy 2008;28:214-224.

20. Chavira DA, Stein MB. Combined psychoeducation and treatment with selective serotonin reuptake inhibitors for youth with generalized social anxiety disorder. J Child Adolesc Psychopharmacol 2002;12:47-54.

21. Walkup JT, Albano AM, Piacentini J, Birmaher B, Compton SN, Sherrill JT, et al. Cognitive behavioral therapy, sertraline, or a combination in childhood anxiety. N Engl J Med 2008;359:2753-2766. 